\title{
Effect of Soaking Pre-treatments on Different Characteristics of Fried Potato Chips
}

\author{
Kalyani Y. Gaikwad and K. A. Athmaselvi \\ ${ }^{1}$ Department of Food Process Engineering, School of Bioengineering, \\ Food Safety and Quality Management, SRM University, Chennai, TN 603 203, India. \\ http://dx.doi.org/10.13005/bbra/2142 \\ (Received: 10 April 2016; accepted: 11 May 2016)

\begin{abstract}
The work studied during this project is effect of different of pre treatments (soaking in salt, citric acid solutions) on the various properties of fried potato chips. Potato slices were pre treated (soaked) and fried in refined sunflower oil at $170^{\circ} \mathrm{C}$ for 20 25min. Diameter, moisture, color and water activity was decreased with the frying time. Control sample also shows similar changes after treatments except color degradation as indirect reduction in color. Generally, pre treatments improved the sensorial properties of potato chips than control samples.
\end{abstract}

Keywords: Potato chips, Hunter color meter, Texture, Sensory analysis, 9point hedonic scale.

Potato (Solanum tuberosum L.) is one of the world's major staple food crops. It fall under the category of tubers and found to be the next rank after cereal grains for human consumption as it provides the major calorie need of people in tropics. As potatoes are very common in tubers used by various categories of people from children to elder ones. In 2003, 310 $\times 10^{12}$ ton potatoes were produced (FAO, 2005). Potatoes are easily available in approximately $80 \%$ of all countries and worldwide production is about 300 millions tons/ year. Particularly US produces 17.4 billion pounds of frozen and French fried potatoes per year (National Potato Council, 1988). In case of potato products the crisps/chips and French fries are most popular with special quality demands than other products.

\footnotetext{
* To whom all correspondence should be addressed. E-mail: athmaphd@gmail.com
}

Deep fat frying of potatoes is extensively used for home made and industrial preparations. These kinds of products found largest application in Ready-to-eat or Ready-to-cook products. The day-to-day life style is changing which predominantly affect the type of food products. Principle behind frying of food or potato chips is based on heat transfer from hot oil, which is removal of moisture and oil uptake by that particular piece (Aguilera \& Gloria-Hernadez, 2000). The desirable and appealing characteristics of fried foods derived from formation of complex structure and some changes like crispy, porous and oily layer of outer crust, which get formed during frying (Rosen \& Hellenas, 2002).

According to the composition of potatoes the reaction occurs in between these components known as non-enzymatic browning or Maillard reaction where the end products are brown in color usually known as melonoidins. As from different researchers some pretreatments affect the formation of these end products by reducing the amount of precursors. 
Due to consumers health concern, they are particular in selection of their food. As some pre-treatments will affect some of these properties, which must be acceptable by ultimate consumer, otherwise product cannot withstand in market compared to other brands. This work aims at determining the influence of various soaking pretreatments on structural properties such as volume (shrinkage), solid density, bulk density, porosity, moisture content, water activity, color changes, textural changes, sensory properties (like color, texture, flavor, overall acceptability) etc.

Hunter color meter used to check color, as it is one of the most important quality parameter to consumer perception (Segnini, Dejmek, \& Oste, 1999). Potato chip color is the result of the Maillard reaction, which depends on the amount of precursors like reducing sugars, proteins, temperatures and frying time (Mackay, Brown, \& Torrence, 1990; Marquez \& Anon, 1986). The color values represented by using $\mathrm{L} * \mathrm{a} * \mathrm{~b} *$ color space, is an International standard for color measurement adopted by the Commission Internationale de I'Eclairage (CIE) in 1976. L* is the Luminance or lightness component that goes from 0 (black) to 100 (white), and parameters a* (from green to red) and $b^{*}$ (from blue to yellow) are the two chromatic components vary from -120 to +120 . The system is based on the spectral sensitivity of human sight and its adaptation to the conditions of light. One of its disadvantages is that it is not intuitive.

\section{MATERIALSANDMETHODS}

Potatoes for the preparation of chips selected from the same vendor to maintain the final properties with minimum diversions/consistency in final fried chips for the ease of study during research. The tubers were stored at normal ambient temperature and manually peeled with hand peeler and cut into disc slices by using slicer. The approximate size/diameter of discs were $6.5 \mathrm{~cm}$ and $1.23 \pm 0.2 \mathrm{~mm}$ thicknesses, which is measured by digital caliper. For studying different parameters all testing carried out for raw potatoes, pre-treated potato discs and fried potato chips to check effect of pre-treatments and frying on final products.

The Hunter color meter is used to check the color of potatoes in raw, pre-treated and fried chips. By comparing color values in between treated sample after frying shows that lightness was more for treated samples than control.

\section{Pre-treatments}

Salt water soaking: Samples were immersed and soaked in salt-water solution with 1 , 2 \& 3\% concentration. The soaking was carried out for 10, 20 and 30minutes for each 1, 2 \& 3\% concentration of salt. Also, the surface moisture gently blotted by tissue paper before frying.

Citric acid soaking: Potato discs were soaked in citric acid solutions with $0.1,0.2 \& 0.3 \%$ concentration. The soaking was carried out for 10 , 20 and 30min at ambient temperature for all mentioned concentrations.

Control treatment: No treatment was applied to potato discs before frying to compare with pre treated potato chis results.

\section{Frying}

A commercial deep fat fryer (Presto Lite) used with temperature controller was used. The oil used for frying was 1.5lit. Refined pure sunflower oil was used as frying medium. The fryer was equipped with a metal mesh basket in which the samples were immersed in the oil and fried. The frying temperature kept $170^{\circ} \mathrm{C}$, higher temperatures resulted in burnt flavor without proper frying. Oil has been replenished after frying of single treatment batch of chips.

\section{Color analysis}

The color of potato discs before and after treatment, after frying measured using a Hunter Lab Colorimeter Labscan XE (Hunter Associates Laboratory, Reston, VA). Color was measured for raw, pre-treated and fried potato chips to compare the variation after each treatment. The average of 5 samples has been taken for accuracy. Using a white calibration plate standardized the colorimeter.

\section{Textural properties}

Texture Analyzer performed a rupture test after frying of potato chips to obtain the results. The test involves applying a direct force to a sample, which placed over the uniform platform. The probe calibrated for height from platform and that $2 \mathrm{~mm}$ probe was moving at constant rate used to break the chips. The data for each sample collected as force $(\mathrm{N})$ and fragiability has been measured. The test performed in triplicates.

Texture analysis is primarily concerned with measurement of the mechanical properties of a product, often a food product relate to its sensory 
properties evaluated by humans. Such equipment is used to evaluate and control the factors affecting quality, processing handling and shelf life, and enabling the producer to understand consumer habits and acceptance criteria. Food texture, through touch, is very important factor for the end consumer, in addition to taste and smell.

\section{Principle}

To physically deform a test sample in a controlled manner and measure its response. The characteristics of the force response are as results of the sample's mechanical properties, which correlate to specific sensory texture attributes. A texture analyzer applies this principle by performing the procedure automatically and indicating the results visually on a digital numerical display or screen.

Texture analyzers perform this test by applying controlled forces to the product and recording its response in the form of force, deformation and time.

\section{Sensory analysis}

Semi trained 10 panel members selected for sensory analysis of chips. The samples were evaluated for color, flavor and texture. Each attribute was evaluated using a 9-Point hedonic scale (9-like extremely, 8-like very much, 7-like moderately, 6-like slightly, 5-neither like nor dislike, 4-dislike slightly, 3-dislike moderately, 2-dislike very much, 1-dislike extremely). The scores received by each samples were then averaged and compared with the average score received by other samples in the series.

\section{RESULTSAND DISCUSSION}

\section{Color analysis}

The values noted for raw, pretreated and

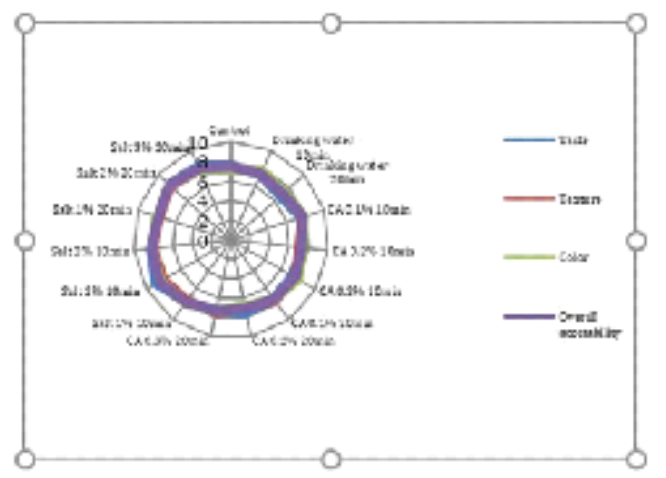

Graph 1. fried chips showing color difference toward lightness. The color of potato chips majored on the white/ lightness as base. The comparison between raw potatoes, pre treated and fried potato chips has been done to check effect of treatments on potato chips. The range of raw potato towards whiteness ranged from 50-65 (for $\mathrm{L}^{*}$ value). The same color analysis for soaked potato chips done where the lightness values increased toward 100, as more the value more the lightness. Compare to raw discs the values ranges from 55 towards 70 . The major comparison, which is important from consumers point of view between fried chips showing lesser value for control than treated potato chips. The overall reduction in values seen than raw and soaked potato chips as after frying color changes towards golden brown. The range decreased from 30-60 for $L^{*}$ values. If comparing in between treatments the gradual decrease in citric acid treatments with increase in concentration for both 10 and 20min soaking. But for the salt solutions with increase in concentration the $\mathrm{L}^{*}$ values increased.

From the graphical representation we can conclude that pretreatments affect the color majorly after frying. These color values can correlate to measure the consumer's acceptability by using sensory analysis tool, which gives market acceptability.

\section{Texture analysis}

The texture checked by using texture analyzer. Applying force and instrument calibrated before checking texture has checked fragility.

\section{Sensory analysis}

Using 9point hedonic scale has done the sensory analysis. The scorecard has been providing to the semi trained panel members. The Taste, color and texture are checked and overall acceptability has been calculated. The score showing that overall acceptability for the sample

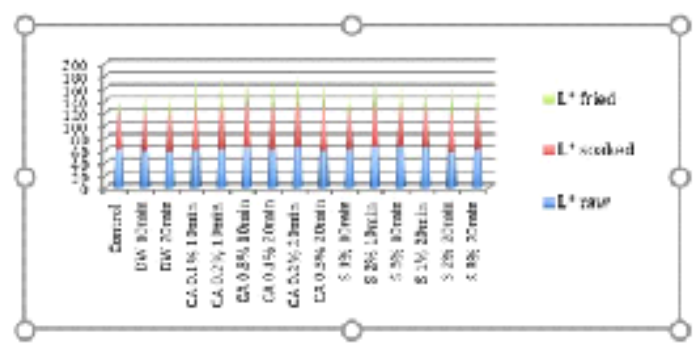

Graph 2. 
pretreated with salt with concentration of $2 \%$ with both 10 and 20min soaking are the most acceptable. Also, the most preferred potato chips are for the salt treatment. The sample with $20 \mathrm{~min}$ drinking water and $0.2 \% 20 \mathrm{~min}$ citric acid solution soaking, gave values with less overall acceptability than control. All the samples compared with the control.

\section{ACKNOWLEDGEMENT}

The authors are thankful to Dr. K. A. Athmaselvi, HOD, Food Process Engineering Department and Dr. M. Vairamani, Dean, School of Bioengineering, SRM University, for providing necessary facilities and continuous support to carry out the research work.

\section{REFERENCES}

1. AACC. (1986). Moisture content. In approved methods of the American Association of Chemists. St Paul, MN: AACC.

2. Aguilera, J. M., \& Gloria-Hernadez, H. Oil absorption during frying of frozen parfried potatoes. Journal of Food Science, 2000; 65, 446-1479.

3. Becalski, A., Lau, B. P., Lewis, D., \& Seaman, S. W. Acrylamide in foods: occurrence, sources, and modeling. Journal of Agricultural and Food Chemistry, 2003; 51, 802-808.

4. Baumann, B., \& Escher, F. Mass and heat transfer during deep fat frying of potato slices, rate of drying and oil uptake. Lebensmittel Wissenschaft und Technologie, 1995; 28, 395403.

5. Food and agriculture organization of the United Nations. FAO statistical databases. http:// faostat.fao.org (accessed July 205).
6. Garayo, J., \& Moreira, R. G. Vacuum frying of potato chips. Journal of Food Engineering, 2002; 55, 181-191.

7. Mackay, G., Brown, J., \& Torrence, C. The processing potential of tubers of the cultivated potato, Solanum tuberosum L. after storage at low temperatures. Potato Research, 1990; 33, 211-218.

8. Ma ìrquez, G., \& An Do ìn, M. C. Influence of reducing sugars and amino acids in the colour development of fried potatoes. Journal of Food Science, 1986; 51, 157-160.

9. Moreira, R. G., Castell-Perez, M. E., \& Barrufet, M. A. Deep- fat frying: Fundamentals and applications. Gaithersburg, MD: Aspen Publishers 1999.

10. National Potato Council. National Potato Council 1988 Potato Statistical Yearbook. National Potato Council, Englewood, CO 1988.

11. Pan, B., \& Castell-Perez, M. E. Textural and visco-elastic changes of canned biscuit dough during microwave and conventional baking. Journal of Food Process Engineering, 1997; 20, 383-399.

12. Rosen, J., \& Hellena s, K. E. Analysis of acrylamide in cooked foods by liquid chromatography tandem mass spectrometry. Analyst, 2002; 127, 880-882.

13. Segnini, S., Dejmek, P., \& O ste, R. A low cost video technique for colour measurement of potato chips. Lebensm.-Wiss. u.-Technol., 1999; 32(4), 216-222.

14. Tareke, E., Rydberg, P., Karlsson, P., Eriksson, S., \& Tornqvist, M. Analysis of acrylamide, a carcinogen formed in heated foodstuffs. Journal of Agricultural and Food Chemistry, 2002; 50, 4998-5006.

15. Toledo, R. R. (1991). Fundamentals of food process engineering (2nd ed.). New York: Van Nostrand Reinhold Company, Inc. 